OPEN ACCESS

Edited by:

Yang Li,

Shenzhen Institutes of Advanced Technology (CAS), China

Reviewed by:

Paola Italiani,

National Research Council (CNR), Italy Liming Wang, Institute of High Energy Physics (CAS),

China

*Correspondence: Mark Geppert mark.geppert@sbg.ac.at

Specialty section:

This article was submitted to Molecular Innate Immunity, a section of the journal Frontiers in Immunology

Received: 31 March 2021 Accepted: 01 June 2021

Published: 15 June 2021

Citation:

Geppert M and Himly M (2021) Iron Oxide Nanoparticles in Bioimaging An Immune Perspective.

Front. Immunol. 12:688927. doi: 10.3389/fimmu.2021.688927

\section{Iron Oxide Nanoparticles in Bioimaging - An Immune Perspective}

\author{
Mark Geppert * and Martin Himly \\ Division of Allergy and Immunology, Department of Biosciences, University of Salzburg, Salzburg, Austria
}

Iron oxide nanoparticles (IONPS) bear big hopes in nanomedicine due to their (potential) applications in tumor therapy, drug delivery or bioimaging. However, as foreign entities, such particles may be recognized by the immune system and, thus, lead to inflammation, hypersensitivity or anaphylactic shock. In addition, an overload with iron is known to cause oxidative stress. In this short review, we summarize the biological effects of such particles with a major focus on IONP-formulations used for bioimaging purposes and their effects on the human immune system. We conclude that especially the characteristics of the particles (size, shape, surface charge, coating, etc.) as well as the presence of bystander substances, such as bacterial endotoxin are important factors determining the resulting biological and immunological effects of IONPs. Further studies are needed in order to establish clear structure-activity relationships.

Keywords: SPIONs, inflammation, oxidative stress, ROS, MRI contrast agent, endotoxin

\section{INTRODUCTION}

Nanoparticles (NPs) are defined as particular entities with a maximum size of $100 \mathrm{~nm}$ in two or three dimensions (1). They can be composed of different organic and inorganic materials such as liposomes, micelles, carbon nanotubes, fullerenes, metalloids, metals and metal oxides. Iron oxide nanoparticles (IONPs) typically consist of a core of a magnetic iron oxide (magnetite, $\mathrm{Fe}_{3} \mathrm{O}_{4}$ or maghemite, $\gamma-\mathrm{Fe}_{2} \mathrm{O}_{3}$ ), surrounded by a coating for their stabilization and can be synthesized by a huge variety of chemical approaches $(2,3)$. During the last decades, IONPs became more and more popular due to their numerous biomedical applications, such as cancer therapy by magnetic-field mediated hyperthermia, drug-delivery, iron replacement therapy or bioimaging techniques (4-6). Although IONPs are generally considered as biocompatible and possess only low cytotoxic potential (7), it is evident that such particles are considered as foreign entities and, thus, may have a variety of effects on the immune system, such as hypersensitivity reactions, immunosuppression or immune stimulation $(8,9)$. The aim of this review is to give an overview on different IONP formulations that are (or have been) clinically applied for imaging purposes and to elaborate on the effects of these particles on human health and the immune system.

\section{IRON OXIDE NANOPARTICLES IN BIOIMAGING}

Due to the magnetic properties of the core and the small particle size, IONPs are superparamagnetic and undergo magnetization only in presence of a magnetic field. This special properties have shown 
to be beneficial for use of such particles as contrast agents in magnetic resonance imaging (MRI) where IONPs produce hypointense (dark) signals in $\mathrm{T}_{2}$-weighted $\mathrm{MR}$ images $(10,11)$. As such, they represent the counterpart to the classical Gadolinium (Gd)-based contrast agents which increase $\mathrm{T}_{1}$ relaxation rates leading to positive (bright) image contrast (12). In recent literature, there is also evidence that ultra-small IONPs $(<5 \mathrm{~nm})$ can be used in both $\mathrm{T}_{1}$ - and $\mathrm{T}_{2}$-weighted MRI $(13,14)$. These findings could appear to be beneficial in the future since Gd-based contrast agents are known to be less biocompatible and can raise the possibility of nephrotoxicity, especially in patients with advanced acute or chronic kidney disease $(15,16)$.

MRI contrast agents can be administered orally or intravenously (17). An example for an orally administered IONP-based contrast agent is Ferumoxsil (Lumirem ${ }^{\circledR}$, GastroMARK $^{\circledR}$ ), which was approved for imaging of the gastrointestinal (GI) tract by the FDA in 1996 but later withdrawn from the market. However, most IONP-based imaging agents are administered via injection. Ferumoxide (Feridex ${ }^{\circledR}$, Endorem ${ }^{\circledR}$ ) and Ferucarbotran (Ciavist ${ }^{\mathrm{TM}}$, Resovist ${ }^{\circledR}$ ) were two contrast agents designed for liver imaging which both became approved in the US as well as in Europe. However, due to different side effects, both were withdrawn from the market in 2008/2009 and only Resovist ${ }^{\circledR}$ is still available in limited countries $(9,18,19)$. Ferumoxtran-10 (Sinerem ${ }^{\circledR}$, Combidex ${ }^{\circledR}$ ) was designed for lymph node imaging in prostate cancer metastasis (20). However, also this earlier FDA-approved agent was withdrawn from the market due to a lack of improved efficacy (19). Ferumoxytol (Feraheme ${ }^{\circledR}$, Rienso ${ }^{\circledR}$ ) was initially approved for treatment of iron deficiency for patients with chronic kidney disease but recently has also been shown to be suitable as contrast aging in MRI, however with no clinical approval yet (21). VSOP C184 and Feruglose (Clariscan ${ }^{\circledR}$ ) were both designed and clinically tested for MR angiography and blood pool imaging but did not reach the level of approval $(22,23)$. Table 1 lists a selection of iron oxide-based contrast agents applied for bioimaging.

Aside from MRI, IONPs can also be applied for a similar but different technique, named magnetic particle imaging (MPI). Here, the particles do not act as a contrast agent but rather are the only source of the signal and the only visualized element (24). By using static and dynamic magnetic fields, the unique magnetic characteristics of IONPs can be used to acquire detailed images without using harmful ionizing radiation. In contrast to MRI,
MPI thereby only images the anatomical sections which were labelled with the IONP tracer $(25,26)$. Thereby it offers threedimensional images with high sensitivity, temporal and spatial resolution. However, to date, MPI is rather experimental, and available scanners are designed for investigation of mouse- and rat-sized animals (26). IONP-formulations like Ferucarbotran (Resovist ${ }^{\circledR}$ ) have been shown suitable for MPI, however, other formulations of IONPs (IONP-micelles) seemed to perform better for this novel technique (27).

\section{BIOCOMPATIBILITY OF IRON OXIDE NANOPARTICLES}

Iron is an essential element and, thus, a life without iron would not be possible. However, overload of iron is also hazardous since it can increase reactive oxygen species (ROS) production via Fenton and Haber-Weiss reactions (28). In the Fenton reaction (1), ferrous iron $\left(\mathrm{Fe}^{2+}\right)$ reacts with hydrogen peroxide $\left(\mathrm{H}_{2} \mathrm{O}_{2}\right)-$ which is, for instance, produced as a side product in mitochondrial respiration (29) - forming ferric iron $\left(\mathrm{Fe}^{3+}\right)$, a hydroxide anion $\left(\mathrm{OH}^{-}\right)$and the extremely reactive hydroxyl radical ( $\mathrm{OH} \cdot)$. The oxidized $\mathrm{Fe}^{3+}$ can be reduced to $\mathrm{Fe}^{2+}$ again by the involvement of a superoxide anion, which will be converted to oxygen (2). The scheme below depicts the reaction equations of both reactions. The concluding final reaction is termed the Haber Weiss reaction - an iron catalyzed reaction, which generates hydroxyl radicals using hydrogen peroxide and superoxide radicals as substrates (3).

$$
\begin{gathered}
\mathrm{Fe}^{2+}+\mathrm{H}_{2} \mathrm{O}_{2} \rightarrow \mathrm{Fe}^{3+}+\mathrm{OH}^{-}+\mathrm{OH} \\
\mathrm{Fe}^{3+}+\mathrm{O}_{2}^{-} \cdot \rightarrow \mathrm{Fe}^{2+}+\mathrm{O}_{2} \\
\mathrm{H}_{2} \mathrm{O}_{2}+\mathrm{O}_{2}^{-} \cdot \rightarrow \mathrm{O}_{2}+\mathrm{OH}^{-}+\mathrm{OH}
\end{gathered}
$$

Due to this reactions, cells have to tightly regulate iron metabolism and have developed numerous pathways and antioxidative defense mechanisms to compete iron-induced stress such as detoxification of $\mathrm{H}_{2} \mathrm{O}_{2}$ by the enzyme catalase or by involvement of the antioxidant glutathione and the enzymes glutathione peroxidase and glutathione reductase or by storing excess of free intracellular iron in the iron storage protein ferritin

\begin{tabular}{|c|c|c|c|}
\hline Formulation & Trade name(s) & Coating & Application(s) \\
\hline Ferumoxide & Feridex $^{\circledR}$, Endorem ${ }^{\circledR}$ & Dextran & Liver imaging \\
\hline Ferucarbotran & Ciavist $^{\mathrm{TM}}$, Resovist ${ }^{\circledR}$ & Carboxydextran & Liver imaging \\
\hline Ferumoxtran-10 & Sinerem ${ }^{\circledR}$, Combidex ${ }^{\circledR}$ & Dextran & Lymph node imaging \\
\hline Ferumoxytol & Feraheme ${ }^{\circledR}$, Rienso ${ }^{\circledR}$ & $\begin{array}{l}\text { Polyglucose sorbitol carboxymethyl } \\
\text { ether }\end{array}$ & $\begin{array}{l}\text { CNS imaging, blood pool imaging, lymph node imaging, Iron deficiency } \\
\text { treatment }\end{array}$ \\
\hline $\begin{array}{l}\text { Citrate-coated very small iron } \\
\text { oxide NP }\end{array}$ & VSOP C184 & Citrate & MR angiography, Blood pool imaging \\
\hline Feruglose & Clariscan $^{\circledR}$ & PEGylated starch & MR angiography, Blood pool imaging \\
\hline Ferumoxsil & $\begin{array}{l}\text { Lumirem }^{\circledR} \\
\text { GastroMARK }\end{array}$ & Siloxane & Oral Gl imaging \\
\hline
\end{tabular}
(30-32). Nevertheless, if these different antioxidative

TABLE 1 | Selected IONP-based contrast agents for MRI. 
mechanisms become overcharged and fail, $\mathrm{OH}$. radicals can induce intracellular damage such as lipid peroxidation, protein oxidation and subsequent degradation and DNA damage, which will lead to cell death through a process called ferroptosis (33). IONPs can be responsible in Fenton reaction-mediated ROS generation either at the particle surface or by intracellular liberation of $\mathrm{Fe}^{2+} / \mathrm{Fe}^{3+}$ ions (34-36). Oxidative stress is frequently described as the main reason for IONP-mediated cytotoxicity as extensively reviewed earlier $(7,37,38)$.

\section{Cellular and Molecular Effects Determined In Vitro}

Cytotoxicity of NPs can be assessed in vitro by a number of different assays addressing different cellular markers. The most prominent assays are the MTT-assay and the WST-1 assay to address the cellular metabolic activity, the $\mathrm{LDH}$ assay to address the cell membrane integrity and the Neutral Red uptake assay to assess lysosomal integrity. In general, the cytotoxicity of IONPs is considered rather low, especially when comparing them with other metal/metal oxide NPs such as silver or copper oxide (39, 40) and only a limited number of studies exists that report toxicity at lower $(<100 \mu \mathrm{g} / \mathrm{mL})$ concentrations $(41,42)$. Interestingly, when moving away from the field of human toxicology, IONPs become much more critical. For example, Zhu and colleagues found that IONPs in concentrations of $10 \mu \mathrm{g} / \mathrm{mL}$ and higher severely affected hatching rate and survival from zebrafish (Danio rerio) while García and co-workers published EC50 values of even less than $1 \mu \mathrm{g} / \mathrm{mL}$ for IONP-toxicity towards Daphnia magna $(43,44)$.

Aside from classical cytotoxicity studies, numerous studies exist that in greater depth investigate the cellular and molecular effects of IONP exposure towards different cell types. As already mentioned above, oxidative stress plays a major role for IONP-related effects. For example, increase of ROS production was found for the IONP formulation Endorem ${ }^{\circledR}$ in human liver cells (45), for Endorem ${ }^{\circledR}$, Resovist $^{\circledR}$ and VSOP C200 in C17.2 neural progenitor cells and PC12 rat pheochromocytoma cells (46) or Feraheme ${ }^{\circledR}$ in human T cells (47). However, also studies exist that show only minor or no ROS production after incubation of human cells with IONPs for bioimaging. Müller and colleagues showed that Ferumoxtran-10 was not toxic to human macrophages, nor did it activate them to produce pro-inflammatory cytokines or induce ROS production (48) and Lindemann and co-workers showed that Ferucarbotran (Resovist ${ }^{\circledR}$ ) did not lead to increased ROS production in head and neck squamous cancer cells (HNSCCs) despite they induced apoptosis (49).

In addition to ROS formation and cytotoxicity, other adverse effects have been reported being caused by IONPs. Dissanayake and co-workers extensively reviewed the potential of IONPs to induce genomic alterations (50). Genotoxicity of IONPs was observed by different types of DNA damage, such as chromosomal aberrations, DNA strand breakage, oxidative DNA damage and mutations (51) or by the formation of micronuclei (52). Jin and colleagues showed that the commercial IONP formulation Feridex ${ }^{\circledR}$ exerted genetic toxicity in human hepatoma (HepG2) cells (53). Soenen and colleagues demonstrated that high concentrations of Endorem ${ }^{\circledR}$, Resovist $^{\circledR}$ and citrate-coated IONPs induced important cytoskeleton and morphology alterations and affected the proliferation of C17.2 neural progenitor cells and primary human blood outgrowth endothelial cells $(46,54)$. Other IONP-related effects that have been reported are cell cycle alterations (55), autophagy (56) or apoptosis $(49,57)$. Figure 1 summarizes entry routes and cellular fate of IONPs in human cells.

\section{Biodistribution, Clearance and Toxicity Determined In Vivo}

Understanding the biodistribution of NPs is a critical point when evaluating their biological and immunological safety (58). The disposition of any compound within an organism can be described by the ADME principle, which stands for absorption, distribution, metabolism and excretion. For IONPs, all these four criteria are strongly dependent on particle characteristics, such as size, size distribution, surface charge, coating molecules and protein corona formation (59). Already more than 30 years ago, the biodistribution of radioactive-labelled Ferumoxide (AMI-25) after injection in rats was studied, with the result that the majority of the particles accumulated in the liver and spleen $1 \mathrm{~h}$ after injection (60). While the clearance of the particles of these organs occurs with half-lives of 3-4 days, the whole body clearance was much longer (44.9 days). In contrast, the blood half-life of these particles was determined to be only $6 \mathrm{~min}$, indicating the rapid uptake and clearance by the mononuclear phagocyte system (MPS) (61). In the same report, the authors also investigated the blood half-life of a second ultrasmall IONP type (size $<10 \mathrm{~nm}$, while AMI-25 was $72 \mathrm{~nm}$ ) and found that these particles remain in the bloodstream with half-lives of $81 \mathrm{~min}$, indicating that IONP size plays a crucial role in particle clearance. This finding was also confirmed by Bourrinet and colleagues who compared $30 \mathrm{~nm}$ Ferumoxtran-10 with the larger Ferumoxides (62).

Apart from IONP size, also the coating and surface charge play a major role in their blood clearance, pharmacokinetics and biodistribution $(58,59)$. In general, IONPs with neutral surface charge are considered having a longer circulation time and a reduced uptake by the MPS due to less opsonization $(63,64)$. Polyethylene glycol (PEG) is often used as a coating agent for IONPs, since it provides a steric stabilization of the particles by a shielding of their surface charge that strongly reduces opsonization and subsequent macrophage uptake (65). Another polymeric coating agent, which is often used as alternative to PEG, is polyvinyl pyrrolidone (PVP) (66). IONPs with positively charged coatings are often cleared much faster from the bloodstream due to differences in protein absorption in comparison with neutral or negatively charged particles (67). It is well known that protein absorption and subsequent protein corona formation has a great impact on the biological identity of NPs and on their effects on living organisms (68). When cleared from the bloodstream, injected IONPs are mainly found in the liver and spleen. However, there is also evidence of IONPs present in the lungs (69), kidney (70), heart (71) and even the brain (72).

IONPs are generally considered as safe and non-toxic in vivo (59), however, such particles can have side effects such as local pain, hypotension, hypersensitivity, anaphylactic shock, vasodilatation and paraesthesia (9) which were the reasons for withdrawal of the earlier clinical applied dextran/carboxydextran-coated IONP-formulations (Feridex ${ }^{\circledR} /$ Endorem $^{\circledR}$, Resovist ${ }^{\circledR} /$ Cliavist $^{\circledR}$, Sinerem ${ }^{\circledR} /$ Combidex $\left.^{\circledR}\right)$. A still approved formulation is 


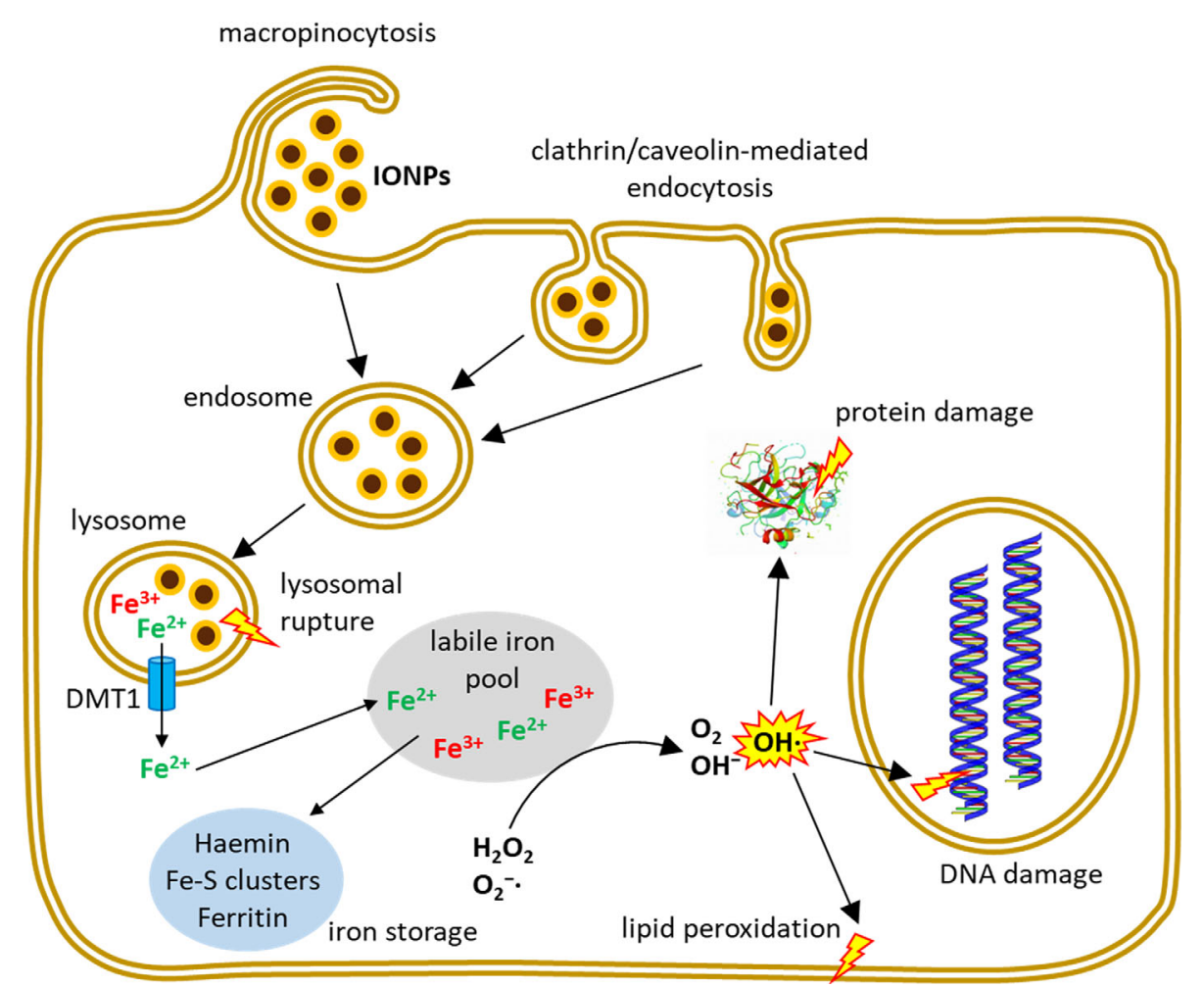

FIGURE 1 | Uptake and intracellular fate of IONPs. Depending on IONP-size and coating and on the investigated cell type, different endocytic mechanisms contribute to the uptake of intact IONPs into the cells where the particles typically enter the endo-lysosomal system. Inside the cell, iron can be liberated from the NPs and contribute to several reactions including Fenton- and Haber-Weiss reactions leading to the formation of hydroxyl radicals which can induce cell damage.

Ferumoxytol (Feraheme ${ }^{\circledR}$, Rienso ${ }^{\circledR}$ in the EU) which is primarily used as iron therapy and has been shown to be tolerable in high doses up to $510 \mathrm{mg}$ per injection (73). However, there is also evidence of risks of hypersensitivity reactions and also the longterm effects seem to be not fully evaluated (74).

\section{IMMUNE EFFECTS OF IRON OXIDE NANOPARTICLES}

Besides cytotoxicity induced through particle-mediated or ironmediated oxidative stress, IONPs may be recognized by the immune system and can, thus, induce different immunological effects. These immune effects are - just like the aforementioned cellular and molecular effects - highly dependent on the particle characteristics. Size, shape, surface charge and particle coating have been described previously to greatly influence the immune effects of IONPs (9). On the one hand, this is explained by the fact that these parameters also influence the IONP biodistribution and toxicokinetic profile (75); one the other hand, certain coatings have been shown to induce certain immune effects. For example, polyethyleneimine (PEI)-coated IONPs have been shown to enhance Th1 polarization of human dendritic cells (DCs) (76), while dextran-coated IONPs have been shown to suppress the proliferation activity of T-lymphocytes (77).
As already mentioned in the previous sections, the first reaction of the human immune system on injected IONPs will be their rapid uptake and elimination by cells of the MPS. One essential component of the MPS are monocytes, which circulate in the peripheral blood and can become activated by different stimuli. Earlier studies have shown that monocytes accumulate dextran-coated IONPs and that this accumulation induces autophagy and an increase in secretion of the pro-inflammatory cytokines Interleukin (IL)-1 $\beta$, IL-6 and Tumor Necrosis Factor (TNF)- $\alpha$ (78). Contradictory results have been published by Grosse and co-workers who showed that 10 and $30 \mathrm{~nm}$ IONPs (coated with a monolayer of oleic acid and a monolayer of amphiphilic polymer) did not lead to elevation of these cytokines end even inhibited LPS-induced pro-inflammatory cytokine production (79). A likely reason for this discrepancy could be the fact that in the latter study, the particles were proven to be free of LPS or other TLR4 agonists, while the authors of the first study did not investigate this. Moreover, the different coatings of the particles can play a role in their different immunological responses. For example, amino-functionalized amino-polyvinyl alcohol-coated IONPs have been shown to increase IL- $1 \beta$ production of human monocytes (80), while starch-coated IONPs did not alter IL-1 $\beta$ and IL-10 secretion but downregulated IL-6 secretion in primary monocytes (81). These differences in observed cytokine profiles shows the need for future studies in order to gain a mechanistic 
understanding of the stimulatory or suppressive effects of IONPs towards human monocytes.

Macrophages are phagocytes, which can be activated in two different ways: classical (M1) or alternative (M2). The main function of M1 macrophages is the detection, phagocytosis and killing of pathogens, apoptotic cells and damaged host cells while M2 macrophages have important functions in tissue repair (9). Aside from this, macrophages can function as antigen-presenting cells (APCs) and thereby connect innate with adaptive immunity. IONPs have been frequently used to label macrophages for MRI, for example in the brain (82), and have been shown to perform better than conventional Gd-based contrast agents in a model of multiple sclerosis (83). On the other hand, it has been shown in vitro that IONPs can also induce oxidative stress and affect cell viability of rat microglia cells (36). Other mechanistic studies reported that IONPs lead to a secretion of IL-12, IL-1 $\beta$ and to upregulation of several genes linked to the M1 phenotype in murine and human macrophages $(80,84,85)$. However, it should be noted here that the IONPs in these studies were not checked for endotoxin contaminations. In a study by Yang and colleagues, the clinically applied IONP formulation Ferucarbotran has been shown to activate RAW264.7 macrophages by an increase in oxidative stress, a decrease in mitochondrial membrane potential and an increase in cell proliferation (86).

IONPs can also affect the function of APCs as shown in a study by Park and co-workers (87). They exposed mice intratracheally with IONPs and found that these particles remained in the lungs for at least 90 days and enhanced the expression of antigen presentation-related proteins such as CD80, CD86, and MHC class II, on APCs in bronchoalveolar lavage (BAL) fluid. Another study by Mou and colleagues reported that positively charged IONPs enhanced antigen cross-presentation of murine DCs while negatively charged IONPs inhibited the DCs' functions and rapidly activated autophagy (88). The clinical IONP-formulation Ferumoxide (Feridex ${ }^{\circledR} /$ Endorem $^{\circledR}$ ) had been shown earlier to affect the viability and migratory properties of DCs, however, only at high concentrations $(89,90)$.

The principal cells of humoral and cellular immune response are the lymphocytes, which specifically recognize and respond to antigens and produce antibodies (B cells) or directly kill infected cells or assist the MPS in destroying them (T cells). The ability of these cells to take up NPs is, generally, considered lower than that of monocytes or macrophages (9). A study by Gaharwar and colleagues reports that isolated rat splenic lymphocytes take up IONPs and that the particles affect cell viability, increase intracellular ROS levels and lipid peroxidation while depleting antioxidative enzymes and glutathione (91). Resovist ${ }^{\circledR}$ has been shown to attenuate Th17 responses in ovalbumin (OVA)sensitized BALB/c mice in vivo and in OVA-primed splenocytes isolated from $\mathrm{BALB} / \mathrm{c}$ mice in vitro (92). This was indicated by a decreased infiltration of CCR6+, IL-6+, IL17+ and ROR- $\gamma+$ cells in inflamed footpads in vivo and by a suppression of the expression of IL-6, IL-17 and ROR-yt in vitro. In another study, Feraheme ${ }^{\circledR}$ has been shown to suppress the immune function of human $\mathrm{T}$ lymphocytes through mitochondrial damage and ROS production (47). In contrast, a Th1-type immune activation was described by
Zhu and co-workers, who exposed mice intratracheally with 4 or $20 \mu \mathrm{g}$ IONPs and reported that NP-induced exosomes were responsible as signaling mediators for this Th1 immune activation (93).

Taken together, it can be stated that there are a number of open questions regarding the complete understanding of IONPs on the functioning of different immune cells. Table 2 sums up the IONP-derived immune effects and the cytokines involved of the studies on different immune cells reviewed in this paper. Results presented in literature are sometimes inconsistent which can be attributed to the use of different IONPs, IONP-coatings, -sizes or -shapes or due to different incubation conditions. Structure-activity relationships are not always clear and future studies are definitely needed in order to systematically evaluate the immune effects of IONPs and the influence of different particle characteristics (9).

\section{CONCLUSIONS AND FUTURE PERSPECTIVES}

Iron oxide nanoparticles (IONPs) possess a variety of biomedical applications, especially in bioimaging. However, these applications came with a price since many of the IONP-containing formulations have shown to cause different side-effects that later resulted in their withdrawal from the market. We herein reviewed the biological and immunological effects of IONPs and concluded that published results often show inconsistencies regarding the effects of such particles. Theses inconsistencies can often be attributed to the particle characteristics (size, shape, surface coating) or the experimental design and incubation conditions (e.g., the presence of bystander substances such as bacterial endotoxins). Thus, quantitative structure-activity relationships (QSARs) for the analysis of such particles are difficult to draw and require more data from future studies involving systematic analysis of well-characterized particles under clearly defined experimental conditions.

TABLE 2 | IONP-derived immune effects and up-/downregulated cytokines of the studies reviewed in this articles.

\begin{tabular}{|c|c|c|}
\hline Cell type & $\begin{array}{l}\text { Immune effects / cytokines } \\
\text { up- or downregulated }\end{array}$ & Referen \\
\hline Monocytes & $\begin{array}{l}\text { Autophagy / IL-1 } \beta(+), \text { IL-6 (+), TNF } \alpha(+) \\
\text { Suppression of LPS-induced NFKB activation } \\
\text { IL-1 } \beta(+) \\
\text { IL-6 (-) }\end{array}$ & $\begin{array}{l}(55) \\
(79) \\
(80) \\
(81)\end{array}$ \\
\hline Macrophages & M1 activation, IL-12 (+) & (84) \\
\hline APCs & $\| \mathrm{L}-1 \beta(+)$ & (85) \\
\hline DCs & Upregulation of several proinflammatory cytokines & (80) \\
\hline Lymphocytes & 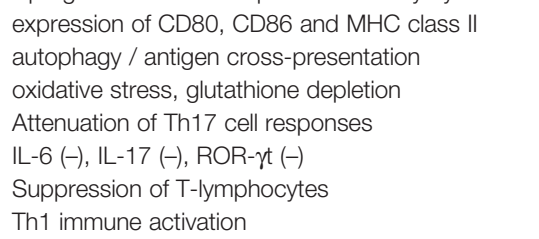 & $\begin{array}{l}(87) \\
(88) \\
(91) \\
(91) \\
(92) \\
(47) \\
(93)\end{array}$ \\
\hline
\end{tabular}




\section{AUTHOR CONTRIBUTIONS}

MG performed literature search and prepared first draft and display items of mini review. $\mathrm{MH}$ was involved in critical discussions of the content and display items, writing and editing of the mini review. All authors contributed to the article and approved the submitted version.

\section{REFERENCES}

1. Auffan M, Rose J, Bottero J-Y, Lowry GV, Jolivet J-P, Wiesner MR. Towards a Definition of Inorganic Nanoparticles From an Environmental, Health and Safety Perspective. Nat Nanotechnol (2009) 4:634-41. doi: 10.1038/ nnano.2009.242

2. Laurent S, Forge D, Port M, Roch A, Robic C, Vander Elst L, et al. Magnetic Iron Oxide Nanoparticles: Synthesis, Stabilization, Vectorization, Physicochemical Characterizations, and Biological Applications. Chem Rev (2008) 108:2064-110. doi: 10.1021/cr068445e

3. Dadfar SM, Roemhild K, Drude NI, Von Stillfried S, Knuchel R, Kiessling F, et al. Iron Oxide Nanoparticles: Diagnostic, Therapeutic and Theranostic Applications. Adv Drug Delivery Rev (2019) 138:302-25. doi: 10.1016/ j.addr.2019.01.005

4. Gupta AK, Gupta M. Synthesis and Surface Engineering of Iron Oxide Nanoparticles for Biomedical Applications. Biomaterials (2005) 26:39954021. doi: 10.1016/j.biomaterials.2004.10.012

5. Martinkova P, Brtnicky M, Kynicky J, Pohanka M. Iron Oxide Nanoparticles: Innovative Tool in Cancer Diagnosis and Therapy. Adv Healthc Mater (2018) 7:1700932. doi: 10.1002/adhm.201700932

6. Vangijzegem T, Stanicki D, Laurent S. Magnetic Iron Oxide Nanoparticles for Drug Delivery: Applications and Characteristics. Expert Opin Drug Delivery (2019) 16:69-78. doi: 10.1080/17425247.2019.1554647

7. Patil RM, Thorat ND, Shete PB, Bedge PA, Gavde S, Joshi MG, et al. Comprehensive Cytotoxicity Studies of Superparamagnetic Iron Oxide Nanoparticles. Biochem Biophys Rep (2018) 13:63-72. doi: 10.1016/ j.bbrep.2017.12.002

8. Dobrovolskaia MA, Shurin M, Shvedova AA. Current Understanding of Interactions Between Nanoparticles and the Immune System. Toxicol Appl Pharmacol (2016) 299:78-89. doi: 10.1016/j.taap.2015.12.022

9. Shah A, Dobrovolskaia MA. Immunological Effects of Iron Oxide Nanoparticles and Iron-Based Complex Drug Formulations: Therapeutic Benefits, Toxicity, Mechanistic Insights, and Translational Considerations. Nanomedicine (2018) 14:977-90. doi: 10.1016/j.nano.2018.01.014

10. Nakamura H, Ito N, Kotake F, Mizokami Y. And Matsuoka, T. (2000). Tumor-detecting Capacity and Clinical Usefulness of SPIO-MRI in Patients With Hepatocellular Carcinoma. J Gastroenterol (2000) 35:849-55. doi: $10.1007 / \mathrm{s} 005350070022$

11. Weinstein JS, Varallyay CG, Dosa E, Gahramanov S, Hamilton B, Rooney WD, et al. Superparamagnetic Iron Oxide Nanoparticles: Diagnostic Magnetic Resonance Imaging and Potential Therapeutic Applications in Neurooncology and Central Nervous System Inflammatory Pathologies, a Review. J Cereb Blood Flow Metab (2010) 30:15-35. doi: 10.1038/ jcbfm.2009.192

12. Zhou Z, Lu ZR. Gadolinium-Based Contrast Agents for Magnetic Resonance Cancer Imaging. Wiley Interdiscip Rev: Nanomed Nanobiotechnol (2013) 5:118. doi: 10.1002/wnan.1198

13. Shen Z, Wu A, Chen X. Iron Oxide Nanoparticle Based Contrast Agents for Magnetic Resonance Imaging. Mol Pharm (2017) 14:1352-64. doi: 10.1021/ acs.molpharmaceut.6b00839

14. Ma X, Wang S, Hu L, Feng S, Wu Z, Liu S, et al. Imaging Characteristics of USPIO Nanoparticles $(<5 \mathrm{Nm})$ as MR Contrast Agent in Vitro and in the Liver of Rats. Contrast Media Mol Imaging (2019) 2019:3687537. doi: 10.1155/ 2019/3687537

15. Ersoy H, Rybicki FJ. Biochemical Safety Profiles of Gadolinium-Based Extracellular Contrast Agents and Nephrogenic Systemic Fibrosis. J Magnetic Resonance Imaging (2007) 26:1190-7. doi: 10.1002/jmri.21135

\section{FUNDING}

This work was funded by the H2020 EU research infrastructure for nanosafety projects NanoCommons (Grant Agreement No. 731032) and NanoRigo (Grant Agreement No. 814530) and by the Allergy-Cancer-BioNano Research Center of the Paris Lodron University of Salzburg.

16. Perazella MA. Current Status of Gadolinium Toxicity in Patients With Kidney Disease. Clin J Am Soc Nephrol (2009) 4:461-9. doi: 10.2215/ CJN.06011108

17. Xiao YD, Paudel R, Liu J, Ma C, Zhang ZS, Zhou SK. MRI Contrast Agents: Classification and Application (Review). Int J Mol Med (2016) 38:1319-26. doi: 10.3892/ijmm.2016.2744

18. Wang YX. Superparamagnetic Iron Oxide Based MRI Contrast Agents: Current Status of Clinical Application. Quant Imaging Med Surg (2011) 1:35-40. doi: 10.3978/j.issn.2223-4292.2011.08.03

19. Wang YX, Idee JM. A Comprehensive Literatures Update of Clinical Researches of Superparamagnetic Resonance Iron Oxide Nanoparticles for Magnetic Resonance Imaging. Quant Imaging Med Surg (2017) 7:88-122. doi: 10.21037/qims.2017.02.09

20. Harisinghani MG, Barentsz J, Hahn PF, Deserno WM, Tabatabaei S, Van De $\mathrm{Kaa} \mathrm{CH}$, et al. Noninvasive Detection of Clinically Occult Lymph-Node Metastases in Prostate Cancer. N Engl J Med (2003) 348:2491-9. doi: 10.1056/NEJMoa022749

21. Bashir MR, Bhatti L, Marin D, Nelson RC. Emerging Applications for Ferumoxytol as a Contrast Agent in MRI. J Magnetic Resonance Imaging (2015) 41:884-98. doi: 10.1002/jmri.24691

22. Klein C, Nagel E, Schnackenburg B, Bornstedt A, Schalla S, Hoffmann V, et al. The Intravascular Contrast Agent Clariscan (TM) (NC 100150 Injection) for 3D MR Coronary Angiography in Patients With Coronary Artery Disease. Magnetic Resonance Mater Phys Biol Med (2000) 11:65-7. doi: 10.1007/ BF02678498

23. Wagner M, Wagner S, Schnorr J, Schellenberger E, Kivelitz D, Krug L, et al. Coronary MR Angiography Using Citrate-Coated Very Small Superparamagnetic Iron Oxide Particles as Blood-Pool Contrast Agent: Initial Experience in Humans. J Magnetic Resonance Imaging (2011) 34:816-23. doi: 10.1002/jmri.22683

24. Dulinska-Litewka J, Lazarczyk A, Halubiec P, Szafranski O, Karnas K, Karewicz A. Superparamagnetic Iron Oxide Nanoparticles-Current and Prospective Medical Applications. Mater (Basel) (2019) 12:617. doi: 10.3390/ma12040617

25. Gleich B, Weizenecker R. Tomographic Imaging Using the Nonlinear Response of Magnetic Particles. Nature (2005) 435:1214-7. doi: 10.1038/ nature 03808

26. Panagiotopoulos N, Duschka RL, Ahlborg M, Bringout G, Debbeler C, Graeser M, et al. Magnetic Particle Imaging: Current Developments and Future Directions. Int J Nanomed (2015) 10:3097-114. doi: 10.2147/ Ijn.S70488

27. Starmans LW, Burdinski D, Haex NP, Moonen RP, Strijkers GJ, Nicolay K, et al. Iron Oxide Nanoparticle-Micelles (ION-Micelles) for Sensitive (Molecular) Magnetic Particle Imaging and Magnetic Resonance Imaging. PloS One (2013) 8:e57335. doi: 10.1371/journal.pone.0057335

28. Kehrer JP. The Haber-Weiss Reaction and Mechanisms of Toxicity. Toxicology (2000) 149:43-50. doi: 10.1016/s0300-483x(00)00231-6

29. Boveris A, Cadenas E. Mitochondrial Production of Hydrogen Peroxide Regulation by Nitric Oxide and the Role of Ubisemiquinone. IUBMB Life (2000) 50:245-50. doi: 10.1080/713803732

30. Aebi H. Catalase In Vitro. Methods Enzymol (1984) 105:121-6. doi: 10.1016/ s0076-6879(84)05016-3

31. Ursini F, Maiorino M, Brigelius-Flohe R, Aumann KD, Roveri A, Schomburg D, et al. Diversity of Glutathione Peroxidases. Methods Enzymol (1995) 252:38-53. doi: 10.1016/0076-6879(95)52007-4

32. Dringen R, Pawlowski PG, Hirrlinger J. Peroxide Detoxification by Brain Cells. J Neurosci Res (2005) 79:157-65. doi: 10.1002/jnr.20280 
33. Latunde-Dada GO. Ferroptosis: Role of Lipid Peroxidation, Iron and Ferritinophagy. Biochim Biophys Acta Gen Subj (2017) 1861:1893-900. doi: 10.1016/j.bbagen.2017.05.019

34. Voinov MA, Sosa Pagan JO, Morrison E, Smirnova TI. And Smirnov, a.I. (2011). Surface-mediated Production of Hydroxyl Radicals as a Mechanism of Iron Oxide Nanoparticle Biotoxicity. J Am Chem Soc (2011) 133:35-41. doi: $10.1021 / j a 104683 \mathrm{w}$

35. Geppert M, Hohnholt MC, Nürnberger S, Dringen R. Ferritin Up-Regulation and Transient ROS Production in Cultured Brain Astrocytes After Loading With Iron Oxide Nanoparticles. Acta Biomater (2012) 8:3832-9. doi: 10.1016/ j.actbio.2012.06.029

36. Petters C, Thiel K, Dringen R. Lysosomal Iron Liberation is Responsible for the Vulnerability of Brain Microglial Cells to Iron Oxide Nanoparticles: Comparison With Neurons and Astrocytes. Nanotoxicology (2016) 10:33242. doi: 10.3109/17435390.2015.1071445

37. Laffon B, Fernández-Bertólez N, Costa C, Brandão F, Teixeira JP, Pásaro E, et al. Cellular and Molecular Toxicity of Iron Oxide Nanoparticles. In: Cellular and Molecular Toxicology of Nanoparticles. Heidelberg, Germany: Springer (2018). p. 199-213.

38. Paunovic J, Vucevic D, Radosavljevic T, Mandic-Rajcevic S, Pantic I. IronBased Nanoparticles and Their Potential Toxicity: Focus on Oxidative Stress and Apoptosis. Chem Biol Interact (2020) 316:108935. doi: 10.1016/ j.cbi.2019.108935

39. Hussain SM, Hess KL, Gearhart JM, Geiss KT, Schlager JJ. In Vitro Toxicity of Nanoparticles in BRL 3A Rat Liver Cells. Toxicol In Vitro (2005) 19:975-83. doi: 10.1016/j.tiv.2005.06.034

40. Karlsson HL, Cronholm P, Gustafsson J, Moller L. Copper Oxide Nanoparticles are Highly Toxic: A Comparison Between Metal Oxide Nanoparticles and Carbon Nanotubes. Chem Res Toxicol (2008) 21:172632. doi: $10.1021 /$ tx800064j

41. Singh N, Jenkins GJS, Asadi R, Doak SH. Potential Toxicity of Superparamagnetic Iron Oxide Nanoparticles (SPION). Nano Rev Exp (2010) 1:5358. doi: 10.3402/nano.v1i0.5358

42. Mahmoudi M, Hofmann H, Rothen-Rutishauser B, Petri-Fink A. Assessing the In Vitro and In Vivo Toxicity of Superparamagnetic Iron Oxide Nanoparticles. Chem Rev (2012) 112:2323-38. doi: 10.1021/cr2002596

43. García A, Espinosa R, Delgado L, Casals E, González E, Puntes V, et al. Acute Toxicity of Cerium Oxide, Titanium Oxide and Iron Oxide Nanoparticles Using Standardized Tests. Desalination (2011) 269:136-41. doi: 10.1016/ j.desal.2010.10.052

44. Zhu X, Tian S, Cai Z. Toxicity Assessment of Iron Oxide Nanoparticles in Zebrafish (Danio Rerio) Early Life Stages. PloS One (2012) 7:e46286. doi: 10.1371/journal.pone.0046286

45. Raschzok N, Muecke DA, Adonopoulou MK, Billecke N, Werner W, Kammer $\mathrm{NN}$, et al. In Vitro Evaluation of Magnetic Resonance Imaging Contrast Agents for Labeling Human Liver Cells: Implications for Clinical Translation. Mol Imaging Biol (2011) 13:613-22. doi: 10.1007/s11307-010-0405-y

46. Soenen SJ, Himmelreich U, Nuytten N, De Cuyper M. Cytotoxic Effects of Iron Oxide Nanoparticles and Implications for Safety in Cell Labelling. Biomaterials (2011) 32:195-205. doi: 10.1016/j.biomaterials.2010.08.075

47. Shah A, Mankus CI, Vermilya AM, Soheilian F, Clogston JD, Dobrovolskai MA. Feraheme (R) Suppresses Immune Function of Human T Lymphocytes Through Mitochondrial Damage and mitoROS Production. Toxicol Appl Pharmacol (2018) 350:52-63. doi: 10.1016/j.taap.2018.04.028

48. Müller K, Skepper JN, Posfai M, Trivedi R, Howarth S, Corot C, et al. Effect of Ultrasmall Superparamagnetic Iron Oxide Nanoparticles (Ferumoxtran-10) on Human Monocyte-Macrophages In Vitro. Biomaterials (2007) 28:1629-42. doi: 10.1016/j.biomaterials.2006.12.003

49. Lindemann A, Lüdtke-Buzug K, Fräderich BM, Gräfe K, Pries R, Wollenberg B. Biological Impact of Superparamagnetic Iron Oxide Nanoparticles for Magnetic Particle Imaging of Head and Neck Cancer Cells. Int J Nanomed (2014) 9:5025. doi: $10.2147 / \mathrm{IJN} . S 63873$

50. Dissanayake NM, Current KM, Obare SO. Mutagenic Effects of Iron Oxide Nanoparticles on Biological Cells. Int J Mol Sci (2015) 16:23482-516. doi: 10.3390/ijms161023482

51. Koedrith P, Boonprasert R, Kwon JY, Kim I-S, Seo YR. Recent Toxicological Investigations of Metal or Metal Oxide Nanoparticles in Mammalian Models In Vitro and In Vivo: DNA Damaging Potential, and Relevant
Physicochemical Characteristics. Mol Cell Toxicol (2014) 10:107-26. doi: 10.1007/s13273-014-0013-z

52. Singh N, Jenkins GJ, Nelson BC, Marquis BJ, Maffeis TG, Brown AP, et al. The Role of Iron Redox State in the Genotoxicity of Ultrafine Superparamagnetic Iron Oxide Nanoparticles. Biomaterials (2012) 33:163-70. doi: 10.1016/ j.biomaterials.2011.09.087

53. Jin M, Ryu J-C, Kim Y-J. Investigation of the Genetic Toxicity by DextranCoated Superparamagnetic Iron Oxide Nanoparticles (SPION) in HepG2 Cells Using the Comet Assay and Cytokinesis-Block Micronucleus Assay. Toxicol Environ Health Sci (2017) 9:23-9. doi: 10.1007/s13530-017-0299-z

54. Soenen SJ, Nuytten N, De Meyer SF, De Smedt SC, De Cuyper M. High Intracellular Iron Oxide Nanoparticle Concentrations Affect Cellular Cytoskeleton and Focal Adhesion Kinase-Mediated Signaling. Small (2010) 6:832-42. doi: 10.1002/smll.200902084

55. Wu J, Sun J. Investigation on Mechanism of Growth Arrest Induced by Iron Oxide Nanoparticles in PC12 Cells. J Nanosci Nanotechnol (2011) 11:1107983. doi: $10.1166 /$ jnn.2011.3948

56. Zhang L, Wang X, Miao Y, Chen Z, Qiang P, Cui L, et al. Magnetic Ferroferric Oxide Nanoparticles Induce Vascular Endothelial Cell Dysfunction and Inflammation by Disturbing Autophagy. J Hazard Mater (2016) 304:18695. doi: 10.1016/j.jhazmat.2015.10.041

57. Berry CC, Wells S, Charles S, Aitchison G, Curtis AS. Cell Response to Dextran-Derivatised Iron Oxide Nanoparticles Post Internalisation. Biomaterials (2004) 25:5405-13. doi: 10.1016/j.biomaterials.2003.12.046

58. Almeida JPM, Chen AL, Foster A, Drezek R. In Vivo Biodistribution of Nanoparticles. Nanomedicine (2011) 6:815-35. doi: 10.2217/nnm.11.79

59. Arami H, Khandhar A, Liggitt D, Krishnan KM. In Vivo Delivery, Pharmacokinetics, Biodistribution and Toxicity of Iron Oxide Nanoparticles. Chem Soc Rev (2015) 44:8576-607. doi: 10.1039/c5cs00541h

60. Weissleder RA, Stark DD, Engelstad BL, Bacon BR, Compton CC, White DL, et al. Superparamagnetic Iron Oxide: Pharmacokinetics and Toxicity. Am J Roentgenol (1989) 152:167-73. doi: 10.2214/ajr.152.1.167

61. Weissleder R, Elizondo G, Wittenberg J, Rabito C, Bengele H, Josephson L. Ultrasmall Superparamagnetic Iron Oxide: Characterization of a New Class of Contrast Agents for MR Imaging. Radiology (1990) 175:489-93. doi: 10.1148/ radiology.175.2.2326474

62. Bourrinet P, Bengele HH, Bonnemain B, Dencausse A, Idee J-M, Jacobs PM, et al. Preclinical Safety and Pharmacokinetic Profile of ferumoxtran-10, an Ultrasmall Superparamagnetic Iron Oxide Magnetic Resonance Contrast Agent. Invest Radiol (2006) 41:313-24. doi: 10.1097/01.rli.0000197669.80475.dd

63. Owens Iii DE, Peppas NA. Opsonization, Biodistribution, and Pharmacokinetics of Polymeric Nanoparticles. Int J Pharm (2006) 307:93102. doi: 10.1016/j.ijpharm.2005.10.010

64. Aggarwal P, Hall JB, Mcleland CB, Dobrovolskaia MA, Mcneil SE. Nanoparticle Interaction With Plasma Proteins as it Relates to Particle Biodistribution, Biocompatibility and Therapeutic Efficacy. Adv Drug Delivery Rev (2009) 61:428-37. doi: 10.1016/j.addr.2009.03.009

65. Jokerst JV, Lobovkina T, Zare RN, Gambhir SS. Nanoparticle PEGylation for Imaging and Therapy. Nanomedicine (2011) 6:715-28. doi: 10.2217/nnm.11.19

66. Huang J, Bu L, Xie J, Chen K, Cheng Z, Li X, et al. Effects of Nanoparticle Size on Cellular Uptake and Liver MRI With Polyvinylpyrrolidone-Coated Iron Oxide Nanoparticles. ACS Nano (2010) 4:7151-60. doi: 10.1021/nn101643u

67. Sakulkhu U, Mahmoudi M, Maurizi L, Salaklang J. And Hofmann, H. (2014). Protein Corona Composition of Superparamagnetic Iron Oxide Nanoparticles With Various Physico-Chemical Properties and Coatings. Sci Rep (2014) 4:5020. doi: $10.1038 /$ srep05020

68. Monopoli MP, Aberg C, Salvati A, Dawson KA. Biomolecular Coronas Provide the Biological Identity of Nanosized Materials. Nat Nanotechnol (2012) 7:779-86. doi: 10.1038/nnano.2012.207

69. Sharma A, Cornejo C, Mihalic J, Geyh A, Bordelon DE, Korangath P, et al. Physical Characterization and In Vivo Organ Distribution of Coated Iron Oxide Nanoparticles. Sci Rep (2018) 8:4916. doi: 10.1038/s41598-018-23317-2

70. Salimi M, Sarkar S, Fathi S, Alizadeh AM, Saber R, Moradi F, et al. Biodistribution, Pharmacokinetics, and Toxicity of Dendrimer-Coated Iron Oxide Nanoparticles in BALB/c Mice. Int J Nanomed (2018) 13:1483-93. doi: 10.2147/IJN.S157293

71. Gaharwar US, Meena R, Rajamani P. Biodistribution, Clearance and Morphological Alterations Of Intravenously Administered Iron Oxide 
Nanoparticles In Male Wistar Rats. Int J Nanomed (2019) 14:9677-92. doi: $10.2147 /$ IJN.S223142

72. Veiseh O, Sun C, Fang C, Bhattarai N, Gunn J, Kievit F, et al. Specific Targeting of Brain Tumors With an Optical/Magnetic Resonance Imaging Nanoprobe Across the Blood-Brain Barrier. Cancer Res (2009) 69:6200-7. doi: 10.1158/0008-5472.CAN-09-1157

73. Fishbane S, Bolton WK, Winkelmayer WC, Strauss W, Li Z, Pereira BJ. Factors Affecting Response and Tolerability to Ferumoxytol in Nondialysis Chronic Kidney Disease Patients. Clin Nephrol (2012) 78:181-8. doi: 10.5414/cn107397

74. Pai AB, Garba AO. Ferumoxytol: A Silver Lining in the Treatment of Anemia of Chronic Kidney Disease or Another Dark Cloud? J Blood Med (2012) 3:7785. doi: $10.2147 / J B M . S 29204$

75. Yang L, Kuang H, Zhang W, Aguilar ZP, Xiong Y, Lai W, et al. Size Dependent Biodistribution and Toxicokinetics of Iron Oxide Magnetic Nanoparticles in Mice. Nanoscale (2015) 7:625-36. doi: 10.1039/c4nr05061d

76. Hoang MD, Lee HJ, Lee HJ, Jung SH, Choi NR, Vo MC, et al. Branched Polyethylenimine-Superparamagnetic Iron Oxide Nanoparticles (BpeiSpions) Improve the Immunogenicity of Tumor Antigens and Enhance Th1 Polarization of Dendritic Cells. J Immunol Res (2015) 2015:706379. doi: 10.1155/2015/706379

77. Easo SL, Mohanan PV. In Vitro Hematological and In Vivo Immunotoxicity Assessment of Dextran Stabilized Iron Oxide Nanoparticles. Colloids Surf B Biointerfaces (2015) 134:122-30. doi: 10.1016/j.colsurfb.2015.06.046

78. Wu Q, Jin R, Feng T, Liu L, Yang L, Tao Y, et al. Iron Oxide Nanoparticles and Induced Autophagy in Human Monocytes. Int J Nanomed (2017) 12:39934005. doi: $10.2147 /$ IJN.S135189

79. Grosse S, Stenvik J, Nilsen AM. Iron Oxide Nanoparticles Modulate Lipopolysaccharide-Induced Inflammatory Responses in Primary Human Monocytes. Int J Nanomed (2016) 11:4625-42. doi: 10.2147/IJN.S113425

80. Strehl C, Gaber T, Maurizi L, Hahne M, Rauch R, Hoff P, et al. Effects of PVA Coated Nanoparticles on Human Immune Cells. Int J Nanomed (2015) 10:3429-45. doi: 10.2147/IJN.S75936

81. Gonnissen D, Qu Y, Langer K, Ozturk C, Zhao Y, Chen C, et al. Comparison of Cellular Effects of Starch-Coated SPIONs and Poly(Lactic-Co-Glycolic Acid) Matrix Nanoparticles on Human Monocytes. Int J Nanomed (2016) 11:5221-36. doi: 10.2147/IJN.S106540

82. Venneti S, Lopresti BJ, Wiley CA. Molecular Imaging of Microglia/ Macrophages in the Brain. Glia (2013) 61:10-23. doi: 10.1002/glia.22357

83. Kirschbaum K, Sonner JK, Zeller MW, Deumelandt K, Bode J, Sharma R, et al. In Vivo Nanoparticle Imaging of Innate Immune Cells can Serve as a Marker of Disease Severity in a Model of Multiple Sclerosis. Proc Natl Acad Sci (2016) 113:13227-32. doi: 10.1073/pnas.1609397113

84. Mulens-Arias V, Rojas JM, Perez-Yague S, Morales MP, Barber DF. Polyethylenimine-coated Spions Trigger Macrophage Activation Through
TLR-4 Signaling and ROS Production and Modulate Podosome Dynamics. Biomaterials (2015) 52:494-506. doi: 10.1016/j.biomaterials.2015.02.068

85. Chen S, Chen S, Zeng Y, Lin L, Wu C, Ke Y, et al. Size-Dependent Superparamagnetic Iron Oxide Nanoparticles Dictate interleukin-1beta Release From Mouse Bone Marrow-Derived Macrophages. J Appl Toxicol (2018) 38:978-86. doi: 10.1002/jat.3606

86. Yang C-Y, Tai M-F, Lin C-P, Lu C-W, Wang J-L, Hsiao J-K, et al. Mechanism of Cellular Uptake and Impact of Ferucarbotran on Macrophage Physiology. PloS One (2011) 6:e25524. doi: 10.1371/journal.pone.0025524

87. Park EJ, Oh SY, Lee SJ, Lee K, Kim Y, Lee BS, et al. Chronic Pulmonary Accumulation of Iron Oxide Nanoparticles Induced Th1-type Immune Response Stimulating the Function of Antigen-Presenting Cells. Environ Res (2015) 143:138-47. doi: 10.1016/j.envres.2015.09.030

88. Mou Y, Xing Y, Ren H, Cui Z, Zhang Y, Yu G, et al. The Effect of Superparamagnetic Iron Oxide Nanoparticle Surface Charge on Antigen Cross-Presentation. Nanoscale Res Lett (2017) 12:52. doi: 10.1186/s11671017-1828-Z

89. Verdijk P, Scheenen TW, Lesterhuis WJ, Gambarota G, Veltien AA, Walczak P, et al. Sensitivity of Magnetic Resonance Imaging of Dendritic Cells for In Vivo Tracking of Cellular Cancer Vaccines. Int J Cancer (2007) 120:978-84. doi: $10.1002 /$ ijc. 22385

90. Dekaban GA, Snir J, Shrum B, De Chickera S, Willert C, Merrill M, et al. Semiquantitation of Mouse Dendritic Cell Migration In Vivo Using Cellular MRI. J Immunother (2009) 32:240-51. doi: 10.1097/CJI.0b013e318197b2a0

91. Gaharwar US, Meena R, Rajamani P. Iron Oxide Nanoparticles Induced Cytotoxicity, Oxidative Stress and DNA Damage in Lymphocytes. J Appl Toxicol (2017) 37:1232-44. doi: 10.1002/jat.3485

92. Hsiao YP, Shen CC, Huang CH, Lin YC, Jan TR. Iron Oxide Nanoparticles Attenuate $\mathrm{T}$ Helper 17 Cell Responses In Vitro and In Vivo. Int Immunopharmacol (2018) 58:32-9. doi: 10.1016/j.intimp.2018.03.007

93. Zhu M, Tian X, Song X, Li Y, Tian Y, Zhao Y, et al. Nanoparticle-Induced Exosomes Target Antigen-Presenting Cells to Initiate Th1-type Immune Activation. Small (2012) 8:2841-8. doi: 10.1002/smll.201200381

Conflict of Interest: The authors declare that the research was conducted in the absence of any commercial or financial relationships that could be construed as a potential conflict of interest.

Copyright $\odot 2021$ Geppert and Himly. This is an open-access article distributed under the terms of the Creative Commons Attribution License (CC BY). The use, distribution or reproduction in other forums is permitted, provided the original author $(s)$ and the copyright owner(s) are credited and that the original publication in this journal is cited, in accordance with accepted academic practice. No use, distribution or reproduction is permitted which does not comply with these terms. 